Prepared for the U.S. Department of Energy

under Contract DE-AC05-76RL01830

\title{
Targeted Energy Efficiency Expert Evaluation (E4) Report: lowa City Federal Building and U.S. Post Office, lowa City, IA
}

J Goddard

N Fernandez

R Underhill

K Gowri

March 2013

Pacific Northwest

NATIONAL LABORATORY

Proudly Operated by Battelle Since 1965 


\section{DISCLAIMER}

This documentation was prepared as an account of work sponsored by an agency of the United States Government. Neither the United States Government nor any agency thereof, nor Battelle Memorial Institute, nor any of their employees, makes any warranty, express or implied, or assumes any legal liability or responsibility for the accuracy, completeness, or usefulness of any information, apparatus, product, or process disclosed, or represents that its use would not infringe privately owned rights. Reference herein to any specific commercial product, process, or service by trade name, trademark, manufacturer, or otherwise does not necessarily constitute or imply its endorsement, recommendation, or favoring by the United States Government or any agency thereof, or Battelle Memorial Institute. The views and opinions of authors expressed herein do not necessarily state or reflect those of the United States Government or any agency thereof.

\section{PACIFIC NORTHWEST NATIONAL LABORATORY \\ operated by \\ BATTELLE \\ for the \\ UNITED STATES DEPARTMENT OF ENERGY \\ under Contract DE-AC05-76RL01830}

Printed in the United States of America

$$
\begin{aligned}
& \text { Available to DOE and DOE contractors from the } \\
& \text { Office of Scientific and Technical Information, } \\
& \text { P.O. Box 62, Oak Ridge, TN 37831-0062; } \\
& \text { ph: (865) 576-8401, fax: (865) 576-5728 } \\
& \text { email: reports@adonis.osti.gov }
\end{aligned}
$$

Available to the public from the National Technical Information Service,

U.S. Department of Commerce, 5285 Port Royal Rd., Springfield, VA 22161

ph: (800) 553-6847, fax: (703) 605-6900

email: orders@ntis.fedworld.gov

online ordering: http://www.ntis.gov/ordering.htm 


\section{Targeted Energy Efficiency Expert Evaluation (E4) Report: lowa City Federal Building and U.S. Post Office lowa City, IA}

JK Goddard

N Fernandez

RM Underhill

K Gowri

March 2013

Prepared for

Federal Energy Management Program

U.S. Department of Energy

under Contract DE-AC05-76RL01830

Pacific Northwest National Laboratory

Richland, Washington 99352 


\section{Executive Summary}

Since 2007, PNNL has conducted Energy Efficiency Expert Evaluations (E4) field training and facility assessments in the Heartland Region (GSA Region 6) buildings to identify low-cost/no-cost opportunities that have the potential to reduce building energy use by up to 10 percent. Based on a follow-up study and feedback from operation and maintenance (O\&M) staff, it was recognized that only 50 percent of the recommended measures were implemented and the lack of control systems expertise was often found to be a major challenge in following up on the E4 recommendations. Hence the region undertook a new initiative in 2011 to perform targeted E4 field audits to identify and train O\&M staff to implement control system measures to realize the energy savings.

The Targeted E4 retuning process uses the building automation system (BAS) and the site metering data (ION or other if different) as the central tool in the investigation, monitoring and diagnosis of the operating condition of the building equipment and systems. The Targeted E4 process begins with virtual meetings between the Targeted E4 Team, Regional Energy Engineer, Building Managers/staff and O\&M contractor to review the BAS and key building systems. These meetings identify BAS trends to set up and save in the building BAS system, along with establishing a complete trend logging process. A minimum of 2-3 weeks of trend data is used before the first site visit to be analyzed by the Targeted E4 team before arriving at the facility. Energy Charting and Metrics (ECAM) tool is used to process the data that results in several charts and graphs highlighting building performance along with individual HVAC system performance (air handlers, terminal boxes, chiller plant, hot water plant, etc.).

During the Targeted E4 process, particular emphasis is made to provide training and implementation assistance to O\&M staff. This training includes setting up and use trends and some graphical diagnostic aids pertinent to economizers and chiller performance. The onsite training emphasizes using trend data to evaluate hot/cold calls as well as diagnosis of the operating conditions of a particular piece of equipment and evaluating the actual schedules of equipment versus the actual hours of operations (including scheduled overtime utilities). Overall, the training focuses on optimizing set points, schedules and sequences to save energy without sacrificing the comfort of the occupants of the building. Training also focuses on steering the operators away from using overrides as a normal operating procedure, and to look at the system as a whole to make energy smart adjustments to the building automation system. O\&M staff are also trained on how to adjust or reverse any control system changes made during the Targeted E4 process, in the event that the changes do not work as expected. In addition, the Targeted E4 team provided phone and email support to the building staff and O\&M staff during the retuning process.

A dedicated regional energy engineer (Linda Baschnagel) is assigned to coordinate and facilitate all Targeted E4 efforts, provide metered data reports and provide support to site staff with implementation of the recommended measures and ongoing monitoring of the building performance. This coordination is found to be critical for the success of the Targeted E4 process.

This report summarizes the targeted E4 measures identified and implemented in the Iowa City Federal Building, Iowa City, IA. The targeted E4 approach involved an initial site visit in March 2012 to identify energy savings opportunities, to discuss the implementation details of each measure with O\&M staff, and to train O\&M staff on setting up trending and enhancing the monitoring capabilities on the 
BAS. Due to an ongoing project to replace and re-commission new air-handlers throughout the building, however, PNNL was not able to work with site staff at the time to implement the measures. A second visit was scheduled in June 2012 after completion of the air-handler replacement project and PNNL followed through with O\&M staff to implement each of the previously-recommended measures and to review each measure to ensure correct implementation. Each targeted E4 measure was modeled in EnergyPlus and expected savings were evaluated before implementing the measures. These savings estimates were validated using metered data available at this site.

A total of 5 energy savings measures were identified and all of them were fully implemented. The estimated energy savings of all the identified measures is 7.7 percent. An analysis of utility billing data since implementation of the five measures in June 2012 shows that in the 6 months following implementation, Iowa City's building energy use decreased by 10.2 percent, or 11.7 percent after weather correction, when compared to the same months in the previous year. Some of this decrease in building energy use is due to the new air-handlers and some is due to the implementation of E4 measures. An attempt is made in this report to determine the amount of savings that is due to each project. This report also includes an action plan for O\&M staff to monitor and improve the effectiveness of the targeted E4 measures identified and implemented. 


\section{Table of Contents}

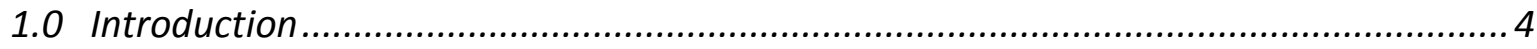

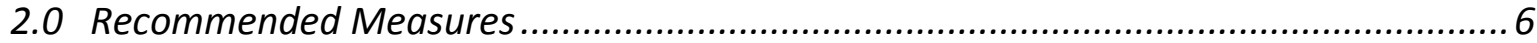

2.1 Measure 1: Shut Minimum Outdoor Air Dampers during Unoccupied Hours .............................6

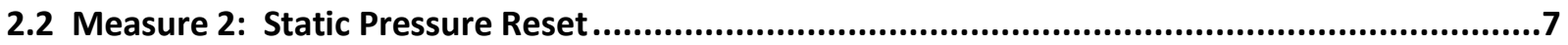

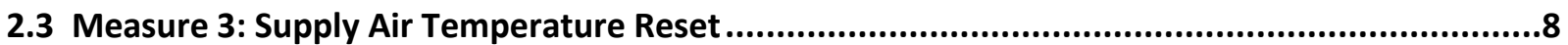

2.4 Measure 4: Hot Water Differential Pressure Reset ..............................................................9

2.5 Measure 5: Chilled Water Temperature Reset...............................................................10

2.6 Measure 6: Miscellaneous Observations and Recommendations: ...........................................11

3.0 Measurement and Verification of Energy Savings .............................................. 12

4.0 Recommended Monitoring Plan...................................................................... 14

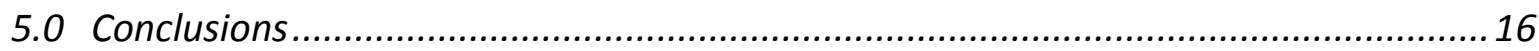




\subsection{Introduction}

As part of a new targeted E4 initiative by the Heartland Region, PNNL staff members conducted an energy efficiency field audit at the Federal and Post Office Building in Iowa City, IA in March 2012.

During the March visit, discussions with GSA staff and review of mechanical, electrical and control systems were performed. The objective of Targeted E4 field visits is to identify low-cost, controls-based operational improvement opportunities and work with building O\&M staff to implement the identified measures and train them during this visit. However, two constraints prevented the E4 team from implementing any of the measures during the initial visit. First, the first floor air handler and VAV upgrade project was not completed at the time of the visit. As a result, these systems had not been handed over to GSA and their control points not entered into the BAS. Second, the E4 visit coincided with the vacation of a key O\&M staff member. This particular staff member is the individual that reviews and approves proposed changes to the BAS. Remaining GSA staff were not able to authorize implementation of any changes to the BAS, a key component of the targeted E4 approach. Hence PNNL's actions during the initial visit were limited to a building walk-down, identification of opportunities and potential measures on the BAS, programming of trending and diagnostic capabilities, and training GSA staff in using these capabilities. Five significant energy saving measures were identified during the first field visit. PNNL recognizes that staff at Iowa City is concerned about potential disruptions to building occupants and to regular O\&M practices. Hence, PNNL selected a list of measures that will have no adverse impact on occupant comfort or O\&M operations, and may potentially improve occupant comfort, O\&M operations and equipment lifetimes.

PNNL scheduled a follow-up visit in June of 2012 to Iowa City, when all newly installed equipment had been commissioned, to implement these identified measures. All five recommended measures where implemented and tested. PNNL continues to monitor and provide support to the building staff as needed in support of the E4 effort.

An EnergyPlus model was developed based on building drawings, information collected during the March 2012 building walk-down, and schedules of operations retrieved from the BAS. Table 1 lists each of the proposed measures described in detail in this report along, with expected savings and implementation status.

Table 1. Summary of Energy Efficiency Measures and the Expected Savings

\begin{tabular}{|l|l|c|l|}
\hline No. & \multicolumn{1}{|c|}{ Description } & $\begin{array}{c}\text { Expected } \\
\text { Savings (\%) }\end{array}$ & \multicolumn{1}{c|}{$\begin{array}{c}\text { Status / } \\
\text { Implementation Notes }\end{array}$} \\
\hline 1 & $\begin{array}{l}\text { Scheduling of 0\% Minimum outdoor air } \\
\text { when unoccupied }\end{array}$ & $\mathbf{2 . 4}$ & Implemented during the follow-up visit in June \\
\hline 2 & Static Pressure Reset & $\mathbf{2 . 1}$ & Implemented during the follow-up visit in June \\
\hline 3 & Supply air temperature reset & $\mathbf{3 . 1}$ & Implemented during the follow-up visit in June \\
\hline 4 & Hot water differential pressure reset & $\mathbf{0 . 4}$ & Implemented during the follow-up visit in June \\
\hline 5 & Chilled water temperature reset & $\mathbf{0 . 1}$ & Implemented during the follow-up visit in June \\
\hline
\end{tabular}

Figure 1 shows the modeled (estimated) energy savings resulting from the implementation of measures 15 individually and total savings when all the five measures are implemented. 


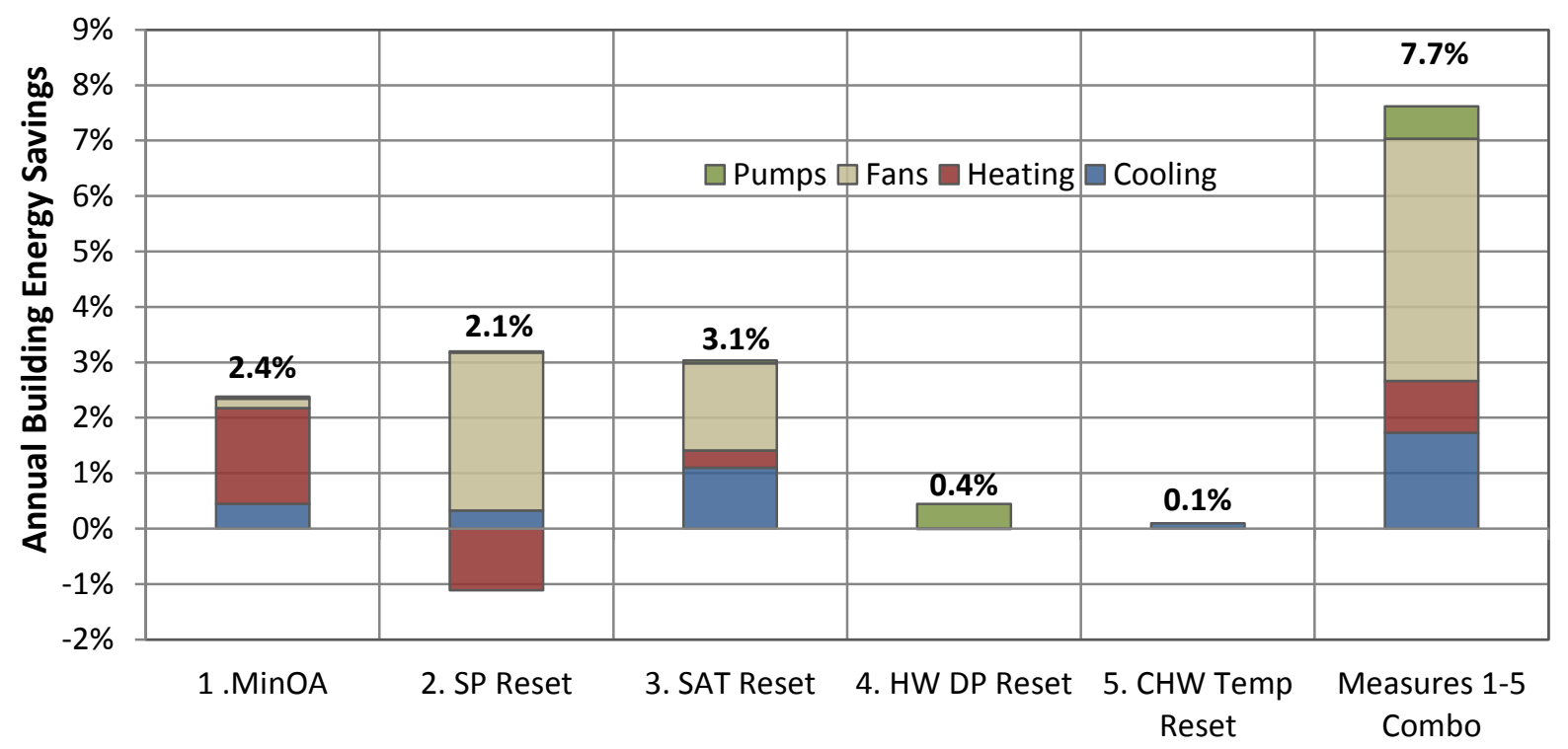

Figure 1. Modeled Annual Building Energy Savings Resulting from Implementation of Targeted-E4 Measures

Section 2 of the report summarizes each of the recommended measures, implementation strategy and estimated energy savings. Section 3 presents the measurement and verification of energy savings using the metered data available from the site and utility billing data obtained from the GSA energy use summary reports. The verification is done by comparing weather adjusted energy use before and after the targeted E4 measures implementation. A list of recommendations for continued monitoring and future implementation actions are presented in Section 4, followed by general conclusions of the impact of targeted E4 in Section 5. 


\subsection{Recommended Measures}

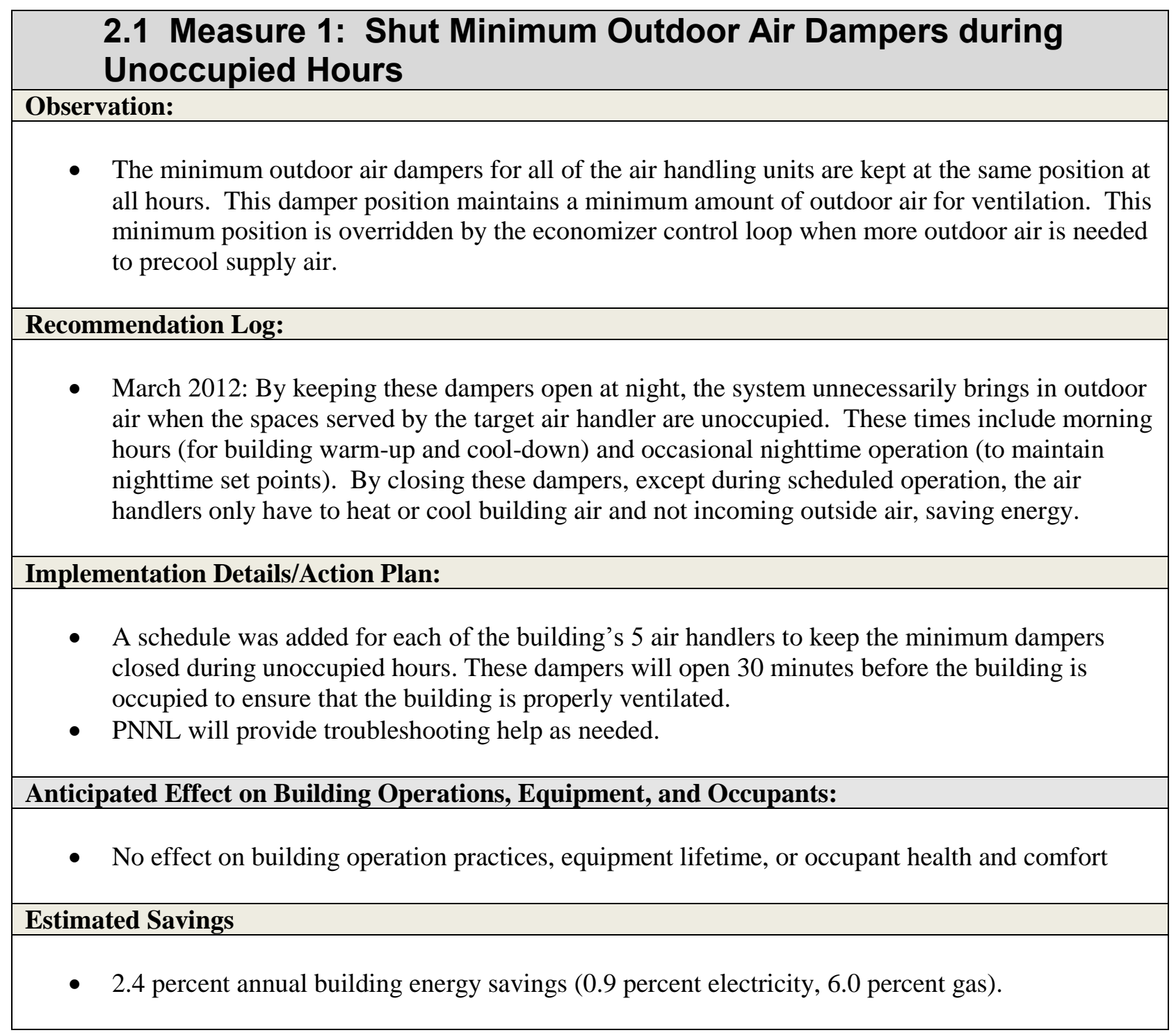




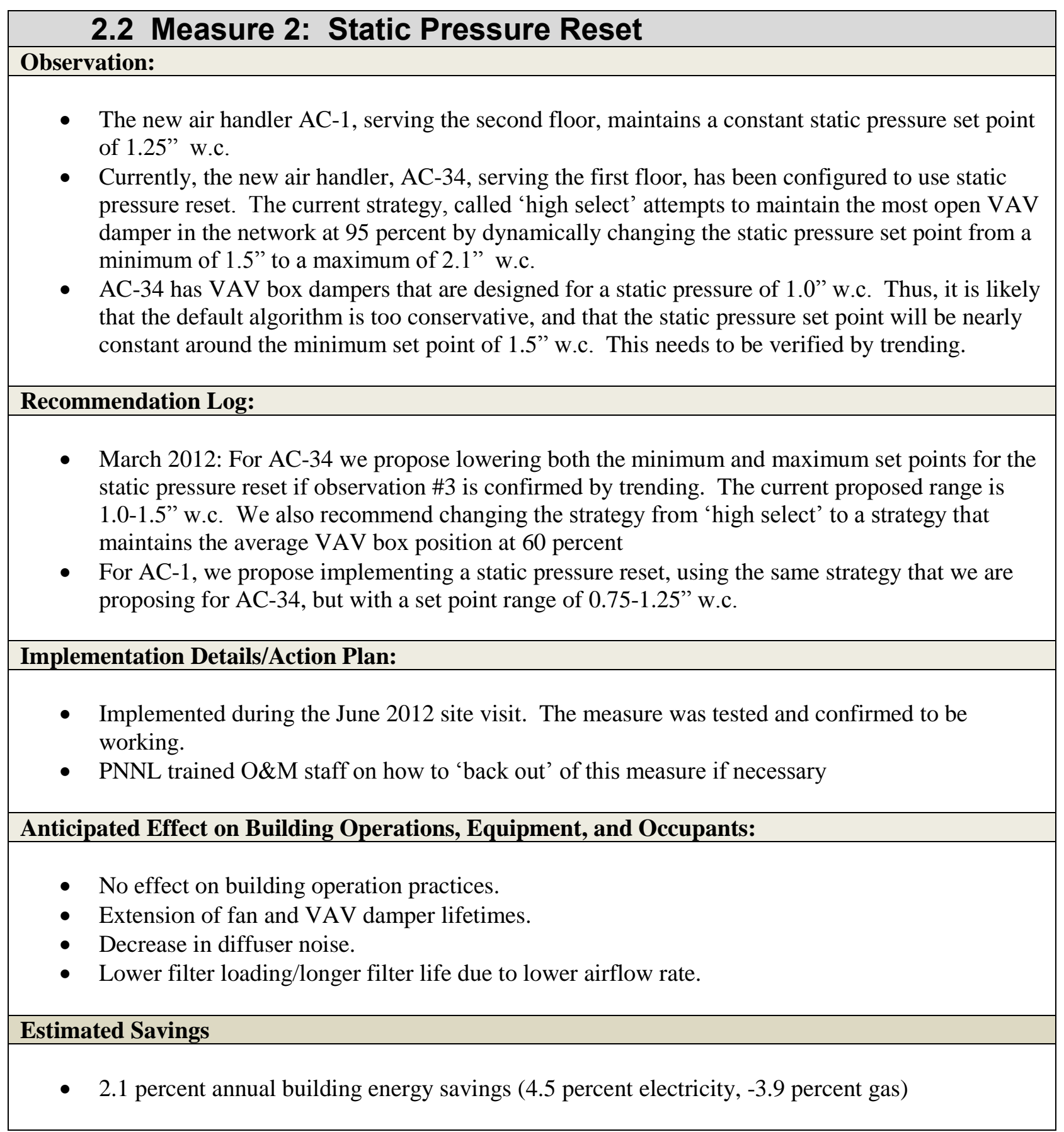




\subsection{Measure 3: Supply Air Temperature Reset \\ Observation: \\ - Currently, the building uses supply air temperature reset with a range of supply air set points of $55-65^{\circ} \mathrm{F}$. The existing control code calculates each VAV box's cooling command value. Based upon the VAV box cooling command values, the discharge air temperature set point will be reset between a low limit $\left(55^{\circ} \mathrm{F}\right)$ when any VAV box has a call for cooling and a high limit $\left(65^{\circ} \mathrm{F}\right)$ when all the VAV boxes are satisfied and not in a cooling mode. \\ - PNNL believes the supply air temperature set point will be stuck around the minimum set point of $55^{\circ} \mathrm{F}$ too often and that the strategy is therefore too conservative. The existing control code calculates each VAV box's cooling command. The algorithms used to come up with the calculated cooling demand only need one VAV box with a deviation from set point to indicate a cooling demand, thus keeping the discharge set point at the lowest reset range $\left(55^{\circ} \mathrm{F}\right)$. It is likely that this will occur only when the building is in a true "setback" condition (cools off at night). However, given the current schedules for the main air handlers (midnight until 6:00 pm, Monday - Saturday), this does not allow for much of a "Night" setback opportunity, therefore this building would seem to (by scheduled design of occupancy hours) always be warm and call for some form of cooling.}

\section{Recommendation Log:}

- March 2012: Change the supply air temperature reset strategy to a zone feedback approach, which is the most responsive form of supply air temperature reset.

- This method uses feedback from 'cooling requests' from the zones and VAV damper positions to determine if the supply air temperature is set too high or too low.

- If two or more zones are calling for cooling, the supply air temperature is lowered incrementally towards a minimum set point of $55^{\circ} \mathrm{F}$.

- If the fan is on and no zones are calling for cooling, the supply air temperature is raised incrementally towards a maximum set point of $70^{\circ} \mathrm{F}$.

\section{Implementation Details/Action Plan:}

- Implemented during the June 2012 site visit. The measure was tested and confirmed to be working.

- PNNL trained O\&M staff on how to 'back out' of this measure, if necessary.

\section{Anticipated Effect on Building Operations, Equipment, and Occupants:}

- In buildings where PNNL has implemented effective supply air temperature reset, staff have frequently observed an improvement in comfort and a reduction in hot/cold complaints because this measure helps to better deliver the 'right' temperature of supply air.

- For zones that are using reheat, there is no effect on the discharge temperature at the zone when the reheat coil is on, and thus no noticeable effect from this measure at those times.

\section{Estimated Savings:}

- $\quad 3.1$ percent annual building energy savings (4.6 percent electricity, 1.1 percent gas) 


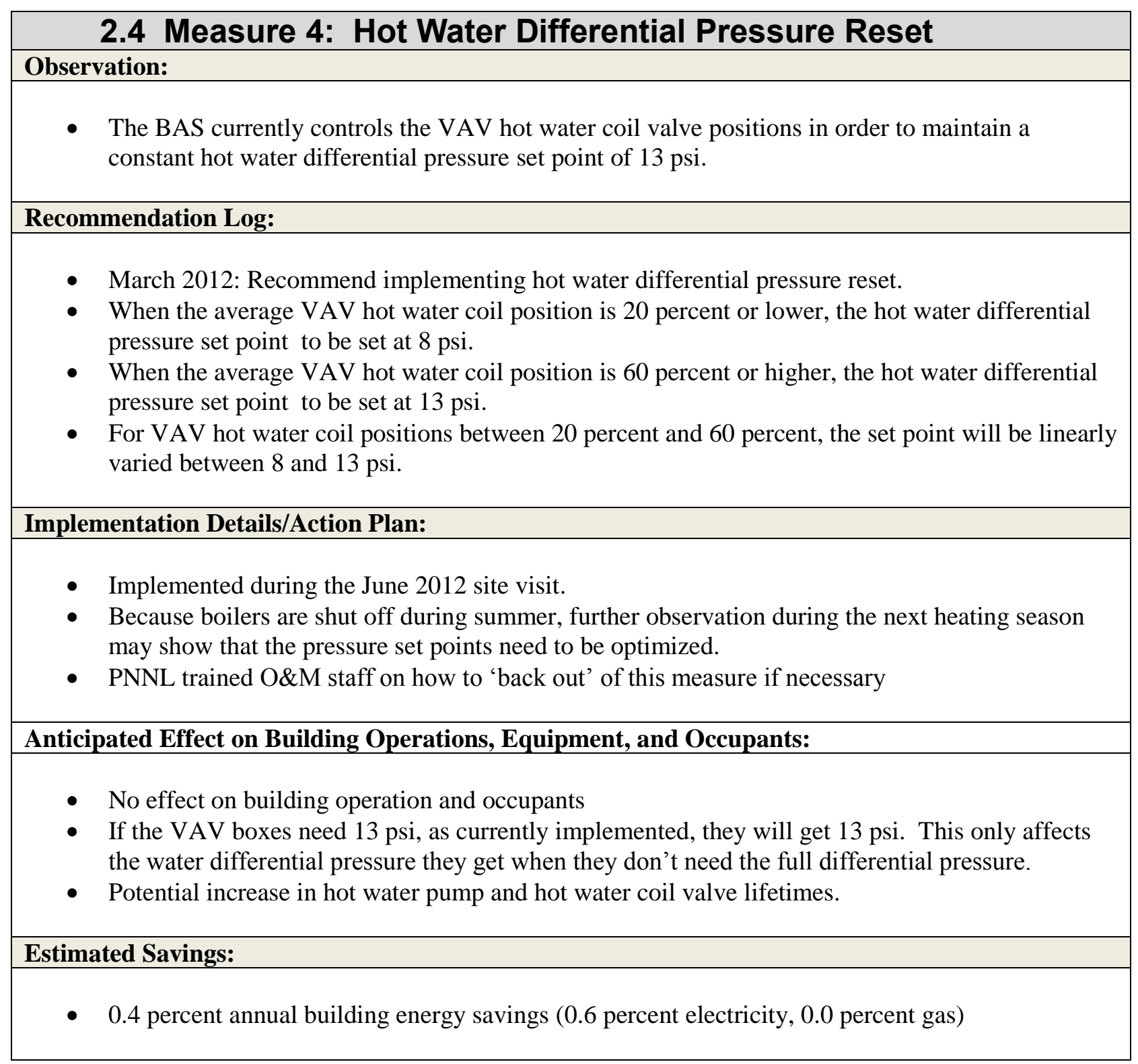




\begin{tabular}{|c|}
\hline 2.5 Measure 5: Chilled Water Temperature Reset \\
\hline 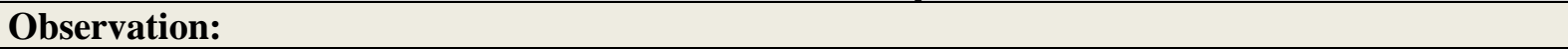 \\
\hline - The chilled water temperature is currently maintained at a constant $45^{\circ} \mathrm{F}$ \\
\hline Recommendation Log: \\
\hline $\begin{array}{l}\text { - March 2012: Recommend implementing chilled water temperature reset } \\
\text { - When the average AHU chilled water coil position is } 15 \text { percent or lower, the chilled water } \\
\text { temperature set point to be set at } 50^{\circ} \mathrm{F} \\
\text { - When the average AHU chilled water coil position is } 80 \text { percent or higher, the chilled water } \\
\text { temperature set point to be set at } 45^{\circ} \mathrm{F} \\
\text { - For VAV hot water coil positions between } 15 \text { percent and } 80 \text { percent, the set point will be } \\
\text { correspondingly varied between } 50^{\circ} \mathrm{F} \text { and } 45^{\circ} \mathrm{F}\end{array}$ \\
\hline Implementation Details/Action Plan: \\
\hline $\begin{array}{l}\text { - Implemented during the June } 2012 \text { visit } \\
\text { - There is problem with the new air handler AHU-1. The supply fan and cooling coil are being } \\
\text { commanded to run at full operating capacity and are not meeting the control set point on days } \\
\text { when the outside temperature is moderate. This is leading to areas of building being hot and } \\
\text { unhappy occupants due to warmer than normal temperature in office areas. The control code } \\
\text { changes from the targeted E4 audits have not contributed to these issues and the chilled water } \\
\text { temperature is set at } 45^{\circ} \mathrm{F} \text {. }\end{array}$ \\
\hline Anticipated Effect on Building Operations, Equipment, and Occupants: \\
\hline $\begin{array}{l}\text { - No effect on building operation, occupants, or equipment lifetimes } \\
\text { - If the cooling coils need } 45^{\circ} \mathrm{F} \text { water, as currently implemented, they will get } 45^{\circ} \mathrm{F} \text { water. This } \\
\text { only affects the water temperature they get during partial load conditions. }\end{array}$ \\
\hline Estimated Savings \\
\hline - 0.1 percent annual building energy savings ( 0.1 percent electricity, 0.0 percent gas) \\
\hline
\end{tabular}




\subsection{Measure 6: Miscellaneous Observations and Recommendations:}

During the field visit, PNNL staff noted the following items which are outside the scope of the targeted E4 effort, but potential O\&M or capital project opportunities. These are provided as informational items for future consideration and do not include detailed implementation strategies or associated analysis.

- UV lamps in AHU-1 are rated at 624 watts and are not interlocked with the supply fan to shut off. This is an energy saving opportunity by turning off the UV lamps when the supply fans are off.

- $\quad \mathrm{AC}-2$ and AC-6 are located in the basement and observed to be aging. They have two drains for each cooling coil and are not piped with a trap and therefore allow air to be pulled into the airhandler fan. They have pneumatic operated dampers and valves. These two air handlers are old and inefficient and should be considered for upgrade/replacement.

- Due to the recently completed HVAC projects, the compressed air system is probably now oversized and should be reviewed for downsizing.

- Domestic Hot Water lines in the basement were noted to be un-insulated. PNNL recommends insulating the exposed hot water pipes.

- The mechanical room housing AHU-34 has un-insulated heating hot water and domestic hot water lines. They should also be insulated.

- The bathroom exhaust fan on the roof has a loud noise, which could either be a bearing or belt issue. The fan noise in the bathroom can be heard as the fan speed is changing. This should be investigated further and fixed.

- There are (4) unit heaters (hot water or electric) located on the 2nd floor, above the drop ceiling. They are not controlled or monitored by Metasys. These should be removed or shut down unless there is a compelling reason for their operation. If needed, the set points should be regulated more closely and only run if the ceiling space temperatures drop below $60^{\circ} \mathrm{F}$.

- The new condensing hot water boilers (Fulton Pulse) recently installed were showing a constant set point of $180^{\circ} \mathrm{F}$. They are controlled by "Mod-Synch" boiler management system that is not connected to Metasys. Though Metasys control has the ability to lock out the heating system (based on $55^{\circ} \mathrm{F}$ cutoff temperature), there is no ability to communicate with "Mod-Synch" and implement hot water temperature set point reset, which could save energy. PNNL staff reviewed the boiler O\&M manual and identified the following potential opportunities to improve the boiler efficiency.

- ModSync can communicate via BACNet (optional). This would allow for connecting to Metasys.

- ModSync will accept a remote 4-20 milliamp control signal. This would allow Metasys to automatically configure the hot water temperature set point based upon demand signals (reheat coil valve positions, etc.).

- ModSync provides a remote enable/disable contact (relay command). This would allow Metasys to automatically enable or disable the boilers based upon occupancy, night setback demand, outside air and other parameters. 


\subsection{Measurement and Verification of Energy Savings}

Figure 2 shows weather-corrected monthly energy savings from EUAS data (electricity and gas for FY12 vs. FY11) compared to the modeled energy savings from implementation of all 5 measures. Because the air-handler replacement project was completed in December 2011, the actual savings is likely attributable to both projects simultaneously. Overall energy savings over this period has been 11.7 percent, while the average monthly modeled energy savings over this period was 6.6 percent. A weathercorrection has been performed on the data to facilitate the comparison, by using the baseline building's patterns of energy consumption with respect to changes in weather (monthly heating and cooling degreedays) and correcting each month to the weather in the TMY2 weather file used for modeling. Iowa City does not have advanced metering, so detailed energy savings verifications are not possible at this time.

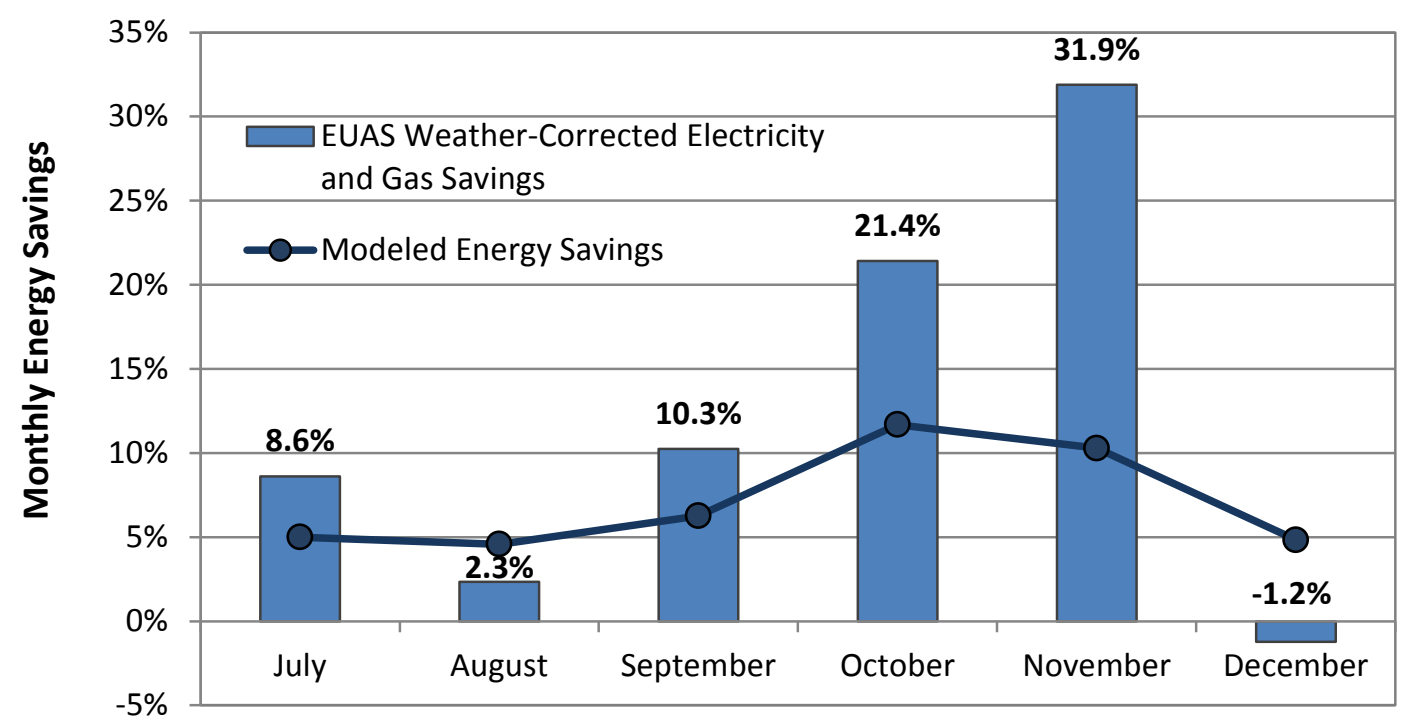

Figure 2: Comparison of Savings: EUAS Weather-Corrected Data vs. EnergyPlus Model Prediction

In an effort to estimate the savings due to the air-handler replacement and compare it with the savings from Targeted-E4 implementation, the energy consumption as a function of heating and cooling demand (heating degree-days and cooling degree-days) was calculated for the 12 months before the ARRA project, 6 months after the ARRA project but before Targeted-E4, and finally for 6 months after TargetedE4. This analysis showed significant impact up to 8 percent additional savings from Targeted E4 measures during the heating season, but virtually no savings during the cooling season.

Though the energy model predicted moderate savings during the cooling season, this has not been realized after Targeted E4 implementation. It has been reported by Iowa City staff and verified during PNNL field visit that the cooling coil valves on the new air handlers were not working as expected. This problem has primary impact during the cooling season (post-Targeted-E4). Although there is enough cooling available from the chillers, not enough cool supply air could be delivered this summer to the building's various zones. This means that a) the zones would have been too hot in general, and the SAT reset algorithm would have been driven to provide the lowest possible supply air temperature, and b) because so many of the zones were hotter than their cooling set points, this may have caused the static pressure reset algorithm to demand that the fans be operated at their maximum static pressure set points. 
Figure 3 shows the rolling 12-month EUI beginning in June 2010. This graph shows that Iowa City had a EUI that was nearly constant around $70 \mathrm{kBtu} / \mathrm{sf}$ from June 2010- November 2011. The air-handler replacement project was completed in late 2011, and the weather-corrected EUI dropped from 70 to 63 by July 2012. A smaller drop down to its current weather-corrected $59 \mathrm{kBtu} / \mathrm{sf}$ ( $54 \mathrm{kBtu} / \mathrm{sf}$ actual consumption) began towards the end of the 2012 cooling season and start of the heating season. Based on the analysis of seasonal demand discussed above, about $1 / 4$ of the 11.7 percent drop in consumption in June-December 2012 is possibly due to the Targeted-E4 measures implemented (about 3.0 percent savings observed so far, which is 4.7 percent lower than expected due to issues with the air-handlers).

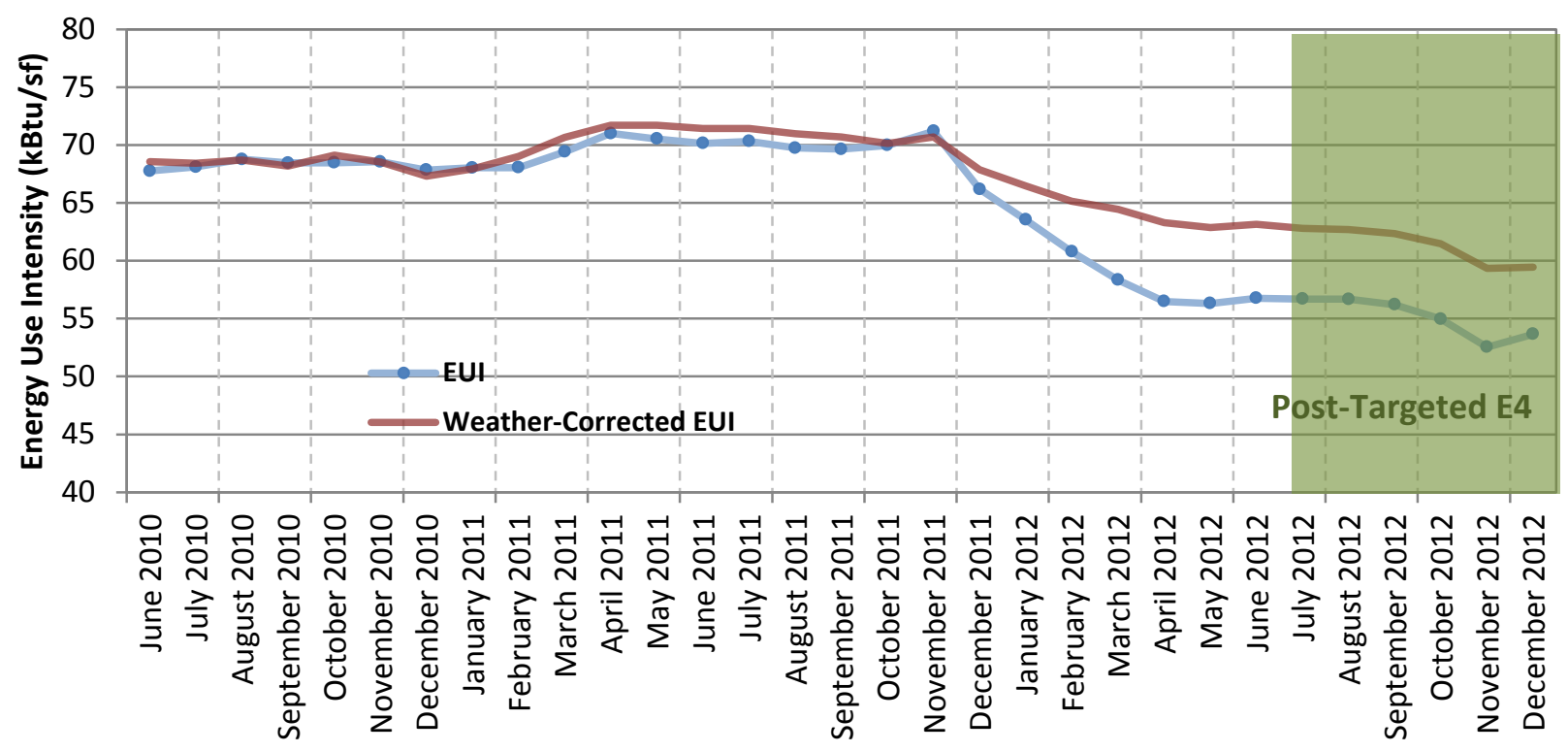

Figure 3. EUAS (Utility Bill) Analysis- Rolling 12-month EUI since January 2011

Figure 4 shows a history of energy consumption at Iowa City during the past five years, using annual energy use intensity (EUI) as the metric for comparison. The chart shows the actual energy use intensity in blue, as well as the weather-corrected EUI in red and the projected weather-corrected EUI for FY13, based on the full modeled savings from Targeted-E4. At the end of FY12, the weather-corrected EUI was at $62.3 \mathrm{kBtu} / \mathrm{sf}$, but as mentioned earlier, it has since dropped to $59.4 \mathrm{kBtu} / \mathrm{sf}$ as of December 2012. Because of an unusually mild weather, the actual EUI is currently $53.6 \mathrm{kBtu} / \mathrm{sf}$. Based on the energy model, the weather corrected annual EUI is expected to be $57.2 \mathrm{kBtu} / \mathrm{sf}$ by June 2013 .

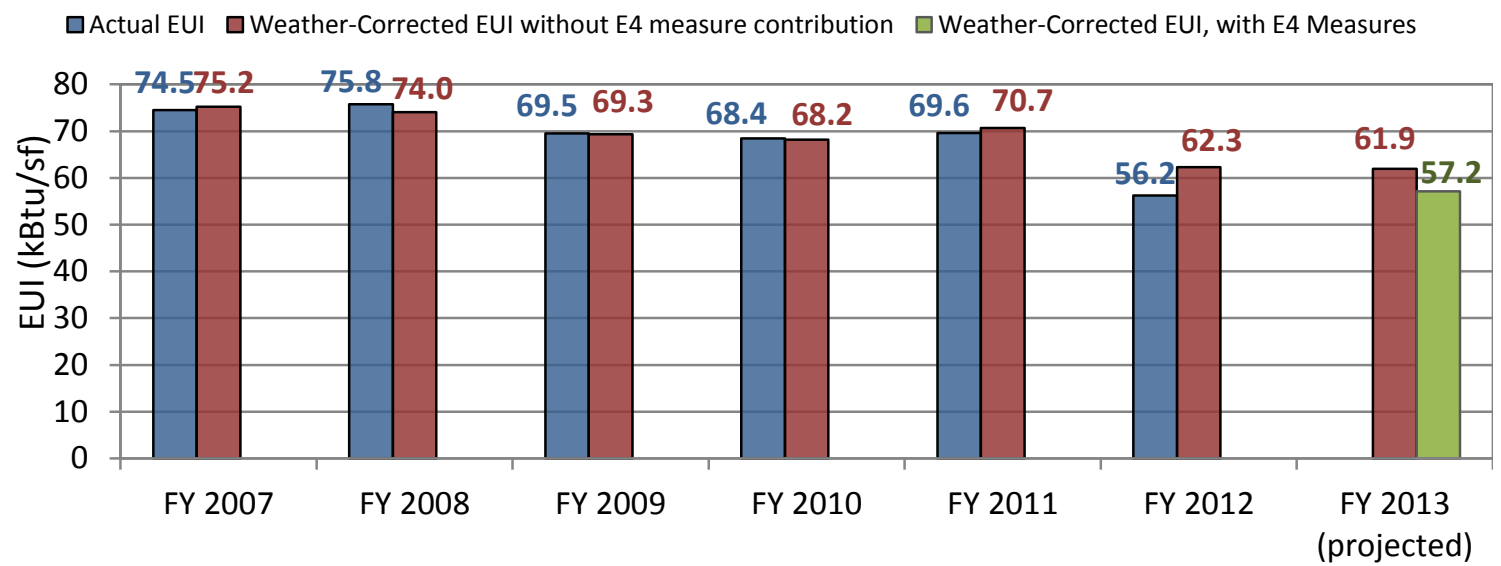

Figure 7. EUI History and Projections for Iowa City Federal Building 


\subsection{Recommended Monitoring Plan}

This section provides recommendations for continued monitoring and implementation of several of the measures 1, 2, 3, 5, 7, 8 and 10 summarized in Section 2 and implemented as part of the Targeted E4 actions taken during FY12.

\section{Measure 1: Shut Minimum Outdoor Air Dampers during Unoccupied Hours}

Monitoring Timeframe: One Day in Winter or Summer 2013

- Trend minimum outdoor air damper status for each of the air-handlers. Verify that the minimum outdoor air dampers are closing at the proper time in the evening and remain shut during nightcycling and morning warm-up/cool- down.

\section{Measure 2: Static Pressure Reset}

Monitoring Timeframe: 1 day in spring 2013

Cold weather periods in the winter are a time when static pressure reset should be very effective at Iowa City. Because the heating system and the VAV system are independent, the supply fan should be running only to deliver ventilation air to the spaces at this time. Zone airflow demands should be low, and static pressure set points are expected to be at or close to minimum programmed levels.

- Make note of current static pressure minimum and maximum set points in Metasys. Are minimum and maximum static pressure set points still at the values indicated in the description of Measure 2?

- Trend the static pressure set point for 2-3 air handlers over the course of a typical business day ( 24 hours). Does the static pressure set point stay near the minimum set point or modulate between the minimum and maximum set point (as intended)?

- If the static pressure set point remains stuck at the maximum set point, can the problem be traced? This should only happen if most of the zone dampers are nearly fully open. If this is not the case, is the static pressure reset algorithm enabled?

- Enabling Further Savings: Are all of the static pressure set points near their minimum values in the winter? Experiment with lowering the minimum static pressure set points to 0.5 " w.c.

\section{Measure 3: Supply Air Temperature Reset}

Monitoring Timeframe: 1 Day in Winter 2012-2013

In the winter, supply air temperatures should be close to their maximum values.

- Make note of current maximum and minimum supply air temperature set points. Are they all set to $70^{\circ} \mathrm{F}$ and $55^{\circ} \mathrm{F}$, respectively?

- Trend the supply air temperature set point for 2-3 air handlers along with zone cooling requests over the course of a typical business day (24 hours). Does the supply air temperature for each air handler stay near $65-70^{\circ} \mathrm{F}$. If not, try to determine why:

$\circ$ Does the supply air temperature increase as expected when there are no zone cooling requests?

- Can you determine why certain zones have cooling requests? Do they have low thermostat set points? Stuck VAV dampers? Poor VAV box airflow? Can any of these problems be remedied easily? 
Measure 4: Hot Water Differential Pressure Reset

Monitoring Timeframe: 1 day in winter 2012-2013

- Trend the hot water differential pressure set point and hot water coil valve positions for 24 hours during a typical winter day. Does the value change between the minimum and maximum set points (8-13 psi)?

- If the differential pressure set point remains at $13 \mathrm{psi}$, are any of the heating coil valves at 100 percent? If not, consider raising the average heating coil valve position associated with the maximum differential pressure set point (currently 60 percent) until one cooling coil valve is at or close to 100 percent.

\section{Measure 5: Chilled Water Temperature Reset}

Monitoring Timeframe: 1 week in Spring 2013

- Trend the chilled water temperature set point and cooling coil valve positions for 1 week in spring with warm weather (high temperatures in the 70 s or $80 \mathrm{~s}$ ). Does the value change between the minimum and maximum set points $\left(45-50^{\circ} \mathrm{F}\right)$ ?

- Double-check that the chilled water temperature only drops to $45^{\circ} \mathrm{F}$ when most of the chilled water coil valves are over 80 percent open.

- Enabling Further Savings: Raise the average cooling coil valve position associated with the maximum chilled water temperature set point (currently 15 percent) to $25-30$ percent. 


\subsection{Conclusions}

Investments in energy savings at Iowa City Federal Building, including ARRA air-handler replacement projects and the implementation of Targeted-E4 re-tuning measures have helped reduce energy consumption by 25 percent since November 2011 from $71.6 \mathrm{kBtu} / \mathrm{sf}$ to $53.6 \mathrm{kBtu} / \mathrm{sf}$. After accounting for weather, the reduction has been 16 percent. In the period of June 2012 through December 2012 following the Targeted-E4 visit, the savings have been 10.2 percent or 11.7 percent after accounting for weather. The relative contributions of the ARRA air-handler project and the Targted-E4 visit is difficult to separate during this period, however, based on the observed patterns of energy savings, Targeted-E4 measures represent approximately 3.0 percent energy savings during that 6 -month period at Iowa City. This estimate is below the 7.7 percent savings originally estimated using the energy model, possibly due to the current issues with the new air-handlers.

In order to sustain the savings and further benefit from the recommended and already implemented measures, PNNL has provided an action plan that requires commitment on the part of the building manager and O\&M contractor for continued monitoring and adjustments to the control system. It is important to highlight the need for dedicated regional staff to facilitate and coordinate the implementation, and monitor the effectiveness of Targeted E4 measures. 